\title{
The Developmental Trajectories of Calling: Predictors and Outcomes
}

\author{
Michelangelo Vianello', Elisa Maria Galliani', Anna Dalla Rosa', \\ and Pasquale Anselmi'
}

\begin{abstract}
There are many open questions concerning the development of calling, and longitudinal empirical evidence is limited. We know that a calling is associated with many beneficial outcomes, but we do not know how it changes through time and what predicts these changes. Previous studies have shown that calling is relatively stable at the sample level. We show that, at the individual level, calling shows huge variations through time. We identified nine developmental trajectories that are typical across facets of calling, and we found evidence that the development of a calling is fostered by the extent to which individuals have lived it out. We also observed that the more a calling has grown over a 2-year period, the more it is lived out during the third year. These results provide support for a developmental model of calling according to which having a calling and living it out reciprocally influence each other. The practical and theoretical implications of these results are discussed.
\end{abstract}

\section{Keywords}

calling, career, change, development, cluster, longitudinal design

In the past, calling has been viewed as a stable construct that can be found or discovered (Bunderson \& Thompson, 2009; Duffy \& Sedlacek, 2007; Wrzesniewski, McCauley, Rozin, \& Schwartz, 1997). Hence, researchers focused on the search for a calling (Duffy \& Sedlacek, 2007) and investigated predictors and outcomes of having and living out a calling (Dobrow, 2013; Duffy, Allan, Autin, \& Bott, 2013). One aspect for which there is almost no knowledge regards how a calling changes through time and how it develops at the individual level (Duffy, Douglass, Autin, \& Allan, 2014). In this article, we investigate whether the results of previous longitudinal studies that investigated sample-average changes in calling are valid for single individuals, using a longitudinal cluster analysis method. We also explore predictors and outcomes of changes in calling, focusing on the relation between living out a calling and the latent growth curve of calling.

\footnotetext{
'Department of Philosophy, Sociology, Education and Applied Psychology, University of Padova, Padova, Italy

Corresponding Author:

Michelangelo Vianello, Department of Philosophy, Sociology, Education and Applied Psychology, University of Padova, via Venezia 14, 35132, Padova, Italy.

Email: michelangelo.vianello@unipd.it
} 


\section{The Construct of Calling}

Career calling is a multidimensional construct that has been defined in many ways (Dalla Rosa, Galliani \& Vianello, 2014). In this article, we adopt a broad conceptualization of calling that includes the key dimensions of most previous conceptualizations (Bunderson \& Thompson, 2009; Dik \& Duffy, 2009; Dobrow \& Tosti-Kharas, 2011; Hagmaier \& Abele, 2012; Praskova, Creed, \& Hood, 2015; Wrzesniewski et al., 1997). Indeed, it has been found that people who feel called to a career or domain are passionate about the calling domain (passion component: Bunderson \& Thompson, 2009; Dobrow \& Tosti-Kharas, 2011; Hagmaier \& Abele, 2012; Wrzesniewski et al., 1997), have a purpose in life (purposefulness component: Dik \& Duffy, 2009; Dobrow \& Tosti-Kharas, 2011; Praskova et al., 2015), sacrifice other areas of their life in favor of their calling (sacrifice component: Bunderson \& Thompson, 2009; Dobrow \& Tosti-Kharas, 2011), feel that the calling's domain is always on their mind (pervasiveness component: Dobrow \& Tosti-Kharas, 2011; Hagmaier \& Abele, 2012; Wrzesniewski et al., 1997), report that their calling comes from something greater than or beyond them (transcendent summons component: Dik \& Duffy, 2009; Hagmaier \& Abele, 2012; Hunter, Dik, \& Banning, 2010; Zhang, Dik, Wei, \& Zhang, 2015; Zhang, Herrmann, Hirschi, Wei, \& Zhang, 2015), and that part of their calling is being useful to others (prosocial orientation component: Bunderson \& Thompson, 2009; Dik \& Duffy, 2009; Hagmaier \& Abele, 2012; Praskova et al., 2015). In terms of outcomes, it has been repeatedly shown that having a calling fosters commitment and engagement with the calling's domain and that individuals with a calling are more satisfied with their job and their life (see, e.g., Dalla Rosa, Galliani, \& Vianello, 2017; Dobrow \& Tosti-Kharas, 2011; Duffy et al., 2013; Hagmaier \& Abele, 2012, for a review).

Given the importance that a calling has in life, it is normal to wonder how and why individuals develop a calling for a job, a life role, or a domain of activities. Drawing on the distinction between objective and subjective careers, Hall and Chandler (2005) theorized that the development of a calling is an ongoing, cyclical process of career self-exploration and discernment, in which selfconfidence, goal setting, and efforts derived from the calling lead to both objective and subjective success that in turn reinforces the calling. Some of these hypotheses were later supported. Duffy, Douglass, Autin, and Allan (2014) found a reciprocal temporal relation between having a calling on the one hand and life meaning and personal growth initiative on the other hand. Duffy, Allan, Autin, and Douglass (2014) found a longitudinal reciprocal relation between living out a calling, career commitment, and finding meaning in one's work. The distinction between the perception of having a calling and the actual experience of living out that calling in one's job or life is critical if we assume that the development of calling is cyclical. "Perceiving a calling refers to the degree to which an individual believes she or he is called to a particular career. [...] Living a calling refers to the degree to which an individual is currently engaging in activities or work that meet this calling" (Duffy \& Autin, 2013, p. 220). The work as a calling theory (WCT; Duffy, Dik, Douglass, England, \& Velez, 2018) recently formalized an assumption that has been alive for a long time in the literature: Having a calling motivates individuals to engage in activities related to the calling's domain in order to live it out. Indeed, calling motivation is defined as the individual's level of motivation to pursue her or his calling (Duffy, Autin, Allan, \& Douglass, 2015). Hence, living out a calling may be seen as a form of subjective success that results from the interaction between individual efforts in pursuing one's calling and favorable environmental opportunities.

Living out a calling may also be seen as a form of self-actualization. Indeed, the connection between living out a calling and self-actualization is very strong and dates back to the latest descriptions of Maslow's theory of needs (1971, p. 40):

Self-actualizing people are, without one single exception, involved in a cause outside their own skin, in something outside of themselves. They are devoted, working at something, something which is very 
precious to them-some calling or vocation in the old sense. They are working at something which fate has called them to somehow and which they work at and which they love, so that the work-joy dichotomy in them disappears [...]. The devotion and dedication is so marked that one can fairly use the old world vocation, calling, or mission to describe their passionate, self-less, and profound feelings for their work. [...] Such vocation-loving individuals tend to identify with their work and to make it into a defining characteristic of the self. [...] The tasks are loved because they embody these (intrinsic) values. [...] The self has enlarged to include aspects of the world and [ ...] the distinction between self- and not-self (outside, other) has been transcended.

According to Maslow (1954), lower order needs such as belonging, love, and respect are deficiency motivated and tend toward homeostasis, whereas self-actualization and self-transcendence are growth motivated. In other words, self-actualization and self-transcendence motivate themselves through engagement in activities that are intrinsically important to the individual, including service to others, and devotion to an ideal or a cause (Koltko-Rivera, 2006).

We argue that calling follows the same developmental process that Maslow theorized for selfactualization and self-transcendence: The more the individuals feel that they are living out a calling, the more they build on and understand their calling, which in turn strengthens their motivation and their efforts to live it out, in a cyclical process that ultimately leads to profoundly meaningful and self-transcendent activities. ${ }^{1}$ This hypothesis is supported by the evidence that the relation between a calling and its positive outcomes is stronger when individuals are living out their calling: Living out a calling both mediates and moderates the impact of perceiving a calling's meaning in work and life, work and life satisfaction, career commitment, and maturity (Dalla Rosa et al., 2017; Duffy et al., 2013; Duffy, Bott, Allan, Torrey, \& Dik, 2012; Duffy \& Dik, 2013). Comparing academics with an unanswered occupational calling to academics who were actually living out their calling and academics with no calling at all, Gazica and Spector (2015) found that the former group reported significantly poorer physical and psychological health. This result suggests that if an individual has a calling, living it out is critical for her or his well-being. Notably, Duffy and Autin (2013) suggested that perceiving a calling fosters living out a calling through the mediation of work volition: People with a calling are more able to live out their calling because of an increased sense of mastery and control in their careers. We expect that living out a calling will strengthen the perception of having a calling, which in turn will lead to increased efforts to live it out.

\section{Evidence on the Development of a Calling}

Empirical evidence on the development of a calling is limited to six longitudinal studies. Five of them followed participants for less than 2 years, and only two of them collected more than two waves of data. These studies focused on the temporal precedence between a calling and related variables, such as meaning in life, career planning, vocational identity, well-being, behavioral involvement, and social comfort in the calling's domain. Hence, they did not specifically focus on intraindividual changes in calling. Rather, they studied sample-level means across time points. This is very common in the psychological literature, where most models are intended to describe processes that operate within each individual but are tested by looking at results averaged across many individuals. It has been shown that this approach may give a misleading picture of what is true for each one (Miller \& Schwartz, 2017), especially with respect to the interpretation of on-average null effects. Previous longitudinal research observed that, on average, callings decrease very slightly through time. Yet Duffy, Manuel, Borges, and Bott (2011) observed a stronger decrease, and Duffy et al. (2014) observed a remarkable increase. Table 1 provides average annualized rates of change for all the longitudinal studies of calling currently published. 
Table I. Average Standardized Rates of Change in Calling.

\begin{tabular}{|c|c|c|c|}
\hline Study & Sample & Time lag & $\begin{array}{c}\text { Annual standardized } \\
\text { mean change }(d)\end{array}$ \\
\hline Dobrow (2013) & $\begin{array}{l}\text { Amateur musicians } \\
\text { Mean age }=17.34, S D=0.94\end{array}$ & $\begin{array}{l}\text { Four waves in } \\
7 \text { years }\end{array}$ & -.08 \\
\hline Duffy et al. (20II) & $\begin{array}{l}\text { First year medical students } \\
\text { Mean age }=22.93, S D=3.64\end{array}$ & $\begin{array}{l}\text { Two waves in } 2 \\
\text { years }\end{array}$ & -.14 \\
\hline Duffy et al. (2014) & $\begin{array}{l}\text { Undergraduate students } \\
\text { Mean age }=20, S D=1.53\end{array}$ & $\begin{array}{l}\text { Two waves in } \\
3 \text { months }\end{array}$ & .21 \\
\hline $\begin{array}{l}\text { Praskova, Hood, and Creed } \\
\quad(2014)\end{array}$ & $\begin{array}{l}\text { Young adults } \\
\text { Mean age }=20.23, S D=2.46\end{array}$ & $\begin{array}{l}\text { Two waves in } \\
6 \text { months }\end{array}$ & -.04 \\
\hline Hirschi and Herrmann (2013) & $\begin{array}{l}\text { University students } \\
\text { Mean age }=23.73, S D=2.40\end{array}$ & $\begin{array}{l}\text { Three waves in } \\
\text { I year }\end{array}$ & -.05 \\
\hline Bott and Duffy (20I5) & $\begin{array}{l}\text { Undergraduate college } \\
\text { students } \\
\text { Mean age }=19.27, S D=1.85\end{array}$ & $\begin{array}{l}\text { Two waves in } \\
6 \text { months }\end{array}$ & .00 \\
\hline
\end{tabular}

Note. When not reported in the original article, the annual rate of change ( $d$ ) has been computed by taking the difference between mean levels of calling across observations and dividing it by the pooled standard deviation of observations across time points. This value has then been annualized by dividing the result by the time lag (in years) of each specific study. This effect size is a standardized mean difference, and can be interpreted using Cohen's (1988) guidelines. Values smaller than .2 indicate small effects, values between .5 and .8 indicate moderate effects, and values greater than .8 indicate large effects. Participants' age statistics were not provided in Duffy et al. (20II). We computed mean and SD of participants' age using public data from the University of Cincinnati, College of Medicine (20I0).

Although average rates of change in calling are small, variation across studies is not trivial and leads to a somewhat uninformative conclusion that, at the sample level, callings may decrease, increase, or even stay the same. Dobrow (2013) and Hirschi \& Hermann (2013) suggested that this may happen for individuals as well, but empirical evidence on intraindividual changes in calling is very limited. Indeed, there is no study that provides a description of the individual trajectories of change or that investigates their shape at the individual level.

We do not know whether individual changes in calling across time are frequent or rare nor whether changes are typically small, moderate, or large. Current empirical evidence on changes in calling may be compatible with many different developmental patterns. Results of previous studies could have been generated by a wide range of individual growth curves. For instance, the results in Dobrow (2013) are compatible with both a scenario in which a large majority of people show a slight decline and a small minority show a steep decline, and one in which half of the participants decrease steeply and the other half increase somewhat less steeply. So far, only two studies have been published that collected at least three waves of data, which are necessary to model some simple shapes of developmental trajectories. One of them (Dobrow, 2013) did not investigate this question. The other one (Hirschi \& Herrmann, 2013) found that, at the sample level, a nonlinear rate of change better fits the data. However, the authors did not investigate further the shapes of the individual trajectories. Specific knowledge on how and why calling changes would inform the theory on the dynamic nature of calling. For instance, a sample-level quadratic shape may suggest that calling is susceptible to change, but then elastically tends to return to the initial level. High intraindividual variability over time may suggest that calling is a state-like construct. On the other hand, high intraindividual stability would suggest that it is a dispositional or trait-like construct. Also, the lack of a general developmental trend across subjects would suggest that calling is not a dispositional construct but the result of continuous, idiosyncratic interactions with the environment. We decided to investigate the development of calling in a 
sample of college students. This choice has been informed by the fact that this phase of life is critical in the development of constructs that are similar to calling, such as vocational interests (Low, Yoon, Roberts, \& Rounds, 2005).

\section{Method}

\section{Participants}

The data used in this article are part of a multiwave data collection that began in 2014 and is currently ongoing. A sample of 5,886 Italian college students of all grades was involved in the first wave, 1,700 students took part in the second wave of data collection, and 881 took part in the third wave of data collection, resulting in a total sample size of 6,370 students. The sample was mainly composed of women $(63.8 \%$, at T1). Participants' mean age at T1 was 23.37 years $(S D=5.39$, min age $=18$ years, max age $=69$ years $)$. All participants were bachelor's $(68 \%$ of the total, min age $=$ 18 years, max age $=64$ years, $\left.M_{\text {age }}=22.55, S D=5.38\right)$ or master's $(30 \%$, min age $=21$ years, $\max$ age $=69$ years, $\left.M_{\text {age }}=25.12, S D=4.90\right)$ students enrolled in 24 different study domains, $44 \%$ had work experience at $\mathrm{T} 1$. In this article, we analyze the responses of the total sample for analyses involving structural equation models (SEMs), estimating missing values by means of full information maximum likelihood algorithms. We adopted a listwise deletion procedure (Nunnally \& Bernstein, 1994) for analyses involving longitudinal clustering procedures, resulting in the exclusion of participants who were totally absent from one wave of data collection. The subsample of students that participated in all three waves $(N=434)$ is composed of bachelor's students $(75 \%$, min age $=$ 18 years, $\max$ age $=57$ years, $\left.M_{\text {age }}=21.12, S D=3.98\right)$ and master's students $(25 \%$, min age $=21$ years, $\max$ age $=59$ years, $\left.M_{\text {age }}=24.51, S D=5.51\right)$. Sixty-nine percent were females, and $38 \%$ were employed.

A second article (Vianello, Dalla Rosa, Anselmi, \& Galliani, 2018) has been published that reports the analyses that were run to validate the multidimensional measure of calling that we employ in the current article. Details on this work, including the open access article and the public data set, can be found here: https:/osf.io/viwsu/. The validation study involved two samples: A sample of working adults (no overlap with the current article) and a sample of college students that partially overlaps with the data set used in the current study. All analyses reported in the validation study (exploratory factor analysis (EFA), confirmatory factor analysis (CFA) multigroup invariance, and external validity) were based on the responses collected at Time 2 (T2; $N=1,700)$, except for the longitudinal invariance test, for which data from all three waves were used $(N=$ 434). The goals of these two manuscripts and the variables involved, with the exception of the multidimensional calling scale, are completely different. A third, unpublished, manuscript (Dalla Rosa, Vianello, \& Anselmi, 2017) has been prepared for reporting the results of a longitudinal path analysis that identifies three predictors of the levels of having a calling 1 year apart. Details regarding this work, including the data set, the manuscript, and the analysis code, can be found here: https://osf.io/5jgrp/. The smaller data set used in the present article $(N=434)$ is the same that we used in Dalla Rosa et al. (2017), which reports that social support, engaged learning, and clarity of professional identity predict the average levels of calling 1 year later. The current article is completely different in scope, analyses, and variables involved. Anonymized data and analysis scripts for the current article are publicly available on the Open Science Framework (https://osf.io/ he $3 \mathrm{zc} /$ ).

\section{Procedure}

Data were collected nonanonymously using an online survey. The second and third waves occurred, respectively, 12 and 24 months after the first data collection. The choice of the time 
lag was informed by previous research showing null or very small changes in calling or closely related constructs such as work passion (see, e.g., Tóth-Király, Bőthe, Jánvári, Rigó, \& Orosz, 2018). Participants were invited to take part in the survey through an e-mail that briefly described the study and provided a link to the survey. The landing page of the web survey presented a more detailed description of the study and the predicted amount of time required to answer the questions. Then, participants were informed of their right to exit the study at any point and have their data deleted, and they were provided with a privacy statement and a contact e-mail. Finally, they were informed that going further in the survey would have been registered as a sign of their willingness to participate nonanonymously and to share their responses with the researchers.

\section{Measures}

Calling. There is currently no agreement on the core components of calling (Thompson \& Bunderson, 2019). Hence, we employed the most comprehensive measure of calling that is currently available: The Unified Multidimensional Calling Scale (UMCS; Vianello et al., 2018). This 22-item Likerttype scale measures both classic and modern components of calling and draws heavily from previous work by Dik, Eldridge, Steger, and Duffy (2012) and by Dobrow and Tosti-Kharas (2011). The UMCS measures seven facets of calling: passion, purposefulness, sacrifice, pervasiveness, prosocial orientation, transcendent summons, and identity. The scale underwent an extensive validation study (Vianello et al., 2018), which provided evidence of satisfactory to excellent reliability and convergent, discriminant, and predictive validity.

The UMCS is the only multidimensional measure of calling for which strict measurement invariance over different observations has been demonstrated. Strict measurement invariance (equal factor loadings, equal indicator intercepts, and equal item uniquenesses; Meredith, 1993) is a key measurement property that should be tested before running any longitudinal studies, and a necessary requirement when scores on a scale are compared across repeated observations. Strict invariance across time is rarely achieved, and the interpretation of change in noninvariant measures can lead to heavily misleading conclusions because observed changes can be attributed to measurement artifacts rather than to true changes in the construct under investigation. The facets that are included in the UMCS have been extensively studied in the literature on calling and are included in the leading theoretical conceptualizations of the construct (Bunderson \& Thompson, 2009; Dik \& Duffy, 2009; Dik, Eldridge, Steger, \& Duffy, 2012; Dobrow \& Tosti-Kharas, 2011; Hagmaier \& Abele, 2012; Praskova et al., 2015; Wrzesniewski et al., 1997). Adopting a conceptualization and measure of calling that employs all of them therefore maximizes the generalizability of results throughout the many different conceptualizations of calling that currently exist in the literature.

The passion component of the UMCS reflects the pleasure and satisfaction that individuals feel in carrying out activities related to the calling's domain (example item: "I am passionate about what I am studying"). Purposefulness reflects how much the engagement in the calling's domain provides the opportunity to find purpose and meaning in life (example item: "I see my academic and professional career as a path to purpose in life"). Sacrifice measures individuals' willingness to sacrifice other areas of their lives to pursue their calling (example item: "I can give up many things to keep studying this subject"). Pervasiveness refers to a constant presence of the calling's domain in individuals' thoughts and consciousness, even when people are not directly involved in domain-related activities (example item: "My studies are always on my mind"). Prosocial orientation refers to other-oriented purposes that guide the involvement in the calling's domain (example item: "The most important part of my future work is helping others to meet their needs"). Transcendent summons measures the presence of a spiritual push toward engaging in activities in the 
calling's domain (example item: "I believe that I have been called to pursue my current line of study"). Finally, identity refers to the importance of the calling in defining who individuals are and the feeling of predetermination and inevitability in pursuing their calling (example item: "What I study is part of my destiny"). The identity scale of the UMCS was not used in this study because this scale was missing in the first wave of data collection. For all the analyses in this article, standardized factor scores are used unless otherwise noted. Having a calling was assessed at each time point, the reliabilities at $\mathrm{T} 1$ for the total sample ranged from .71 to .85 . The estimation of factor scores was conducted in MPlus using full information maximum likelihood to handle partially missing data.

Living out a calling. The degree to which students felt they were currently living out their calling was assessed at T2 and T3 with the item "Are you living out your calling in the program you are enrolled in?" evaluated on a 4-point scale ranging from not at all to very much.

This single-item measure was validated on an independent sample $\left(N=205, M_{\text {age }}=46.8, S D=\right.$ $11.18 ; 32.4 \%$ females), in which we measured living a calling with the scale developed by Duffy, Allan, and Bott (2012). Details on this study, including the codebook, the description of the study, and the public data set, can be found here: https://osf.io/ed9yh/. In line with previous studies $\left(r_{\mathrm{xx}}=\right.$ .94 in Duffy \& Autin, 2013; $r_{\mathrm{xx}}=.95$ in Duffy et al., 2012 and in Duffy et al., 2013), the multi-item measure exhibited very high internal consistency $\left(r_{\mathrm{xx}}=.95\right)$. The Spearman Brown prophecy formula (Nunnally \& Bernstein, 1994, pp. 263-264) indicated that single-item measures extracted from this scale would have been satisfactorily reliable $\left(r_{\mathrm{xx}}=.76\right)$. Hence, the item with the highest factor loading (.91) and the highest item-total correlation $(r=.87)$ were selected for inclusion in this study.

We also checked whether in this study correlations with living a calling are attenuated by unreliability. Previous research showed that living a calling correlates with the presence of a calling (Duffy et al., 2013; Duffy et al., 2012; Duffy \& Autin, 2013; $r$ ranged between .32 and .49) and academic satisfaction (Duffy, Allan, \& Bott, 2012; $r=.29$ ). In the current study, we found living a calling to relate in the expected directions and with similar or stronger intensity to presence of a calling $\left(r_{\mathrm{t} 2}=.54 ; r_{\mathrm{t} 3}=.42\right)$ and academic satisfaction $\left(r_{\mathrm{t} 2}=.43 ; r_{\mathrm{t} 3}=.44\right)$. Lastly, the single-item measure of living a calling that we employed shows a test-retest reliability of $r_{\mathrm{xx}}=.54$, which is in line with a previous result obtained using the multi-item measure $\left(r_{\mathrm{xx}}=.53\right.$; Duffy, Allan, Autin, \& Douglass, 2014).

Academic satisfaction. The degree to which participants were satisfied with their study program was measured at T2 and T3 with the question: "How much are you satisfied with your study program?," evaluated on a 4-point scale ranging from not at all to very much. It has been shown that a global rating measure of satisfaction is likely to provide a more tailored picture of participants' view (Nagy, 2002; Scarpello \& Campbell, 1983). We observed a test-retest reliability of .58 after 1 year and correlations in the expected direction (Duffy, Allan, \& Bott, 2012; Duffy \& Autin, 2013; Duffy et al., 2012; Duffy et al., 2013; Nauta, 2007; Strahan \& Credé, 2015) with living a calling $\left(r_{\mathrm{t} 2}=.43\right.$; $\left.r_{\mathrm{t} 3}=.44\right)$, dropout intention $\left(r_{\mathrm{t} 2}=-.19 ; r_{\mathrm{t} 3}=-.21\right)$, and grade point average $\left(r_{\mathrm{t} 2}=.13 ; r_{\mathrm{t} 3}=.20\right)$.

Dropout intentions. Participants' intention to drop out of college was evaluated at each time point with 1 item asking them to choose the option that best described their willingness to abandon their studies on a scale from 1 (I am going to finish my study program) to 4 (I am going to leave my study program $)$. Correlations between scores on this single-item measure after 1 year $\left(r_{\mathrm{t} 1-\mathrm{t} 2}=.31, r_{\mathrm{t} 2-\mathrm{t} 3}\right.$ $=.53$, and $r_{\mathrm{t} 1-\mathrm{t} 3}=.33$ ) were in line with previous findings (Eicher, Staerklé, \& Clémence, 2014; Perez, Cromley, \& Kaplan, 2014). Test-retest reliability was $r_{\mathrm{xx}}=.49$ (change-free estimate: Heise, 1969, Equation 9). This measure correlates in the expected direction (Aitken, 1982; Strahan \& 
Credé, 2015) with academic satisfaction $\left(r_{\mathrm{t} 2}=.27 ; r_{\mathrm{t} 3}=.24\right)$ and grade point average $\left(r_{\mathrm{t} 1}=.16\right.$; $\left.r_{\mathrm{t} 2}=.18 ; r_{\mathrm{t} 3}=.17\right)$.

Employment status and work experience. We asked participants to report if they had worked or were currently working at the time of the data collection. For those who had work experience, we asked to report how long they had worked or have been working. The response scale was from 1 to $7(1=$ some days; $2=a$ few weeks $; 3=1$ month $; 4=a$ few months $; 5=1$ year; $6=a$ few years; 7 = many years).

Age, gender, employment status, work experience, and mean grade were assessed at each time point. All single-item measures had to be employed to limit the number of items in the questionnaire and the time needed to answer. Too many questions would have had detrimental effects on both the partial nonresponse rate and the mortality of participants across the three waves of data collection (Drolet \& Morrison, 2001).

\section{Results}

\section{Attrition Analysis}

We analyzed the nonrandom sampling effect of subject attrition following the strategies proposed by Goodman and Blum (1996). We analyzed whether attrition affected the probability of participating in all data collections based on measures of calling; work experience; dropout intention; mean grade; employment status, age, and gender at T1 and T2; and academic satisfaction and living out a calling at T2. Then, we analyzed whether reducing the sample to only those who participated in the three data collection points had an effect on means and variances.

Results suggest that the only nontrivial differences between those who remained and those who dropped out of the study regarded age $(d=.28)$ and work experience $(d=.26)$. Specifically, students who provided data at all three observations were younger $\left(M_{\text {age }}=21.97\right)$ and had shorter work experience $(M=5.09)$ than students who dropped out earlier than T3 $\left(M_{\text {age }}=23.49\right.$; mean work experience $=5.41$ years). This probably occurred because students who graduated before $\mathrm{T} 3$ were less likely to read our invitation to the study.

\section{Calling: State or Trait? Relative Versus Absolute Changes at the Sample Level}

Our first aim was to investigate the sample-average changes in calling and compare them with previous longitudinal studies. In the current study, the standardized annual rate of change from T1 to T3 ranged from $d=-.09$ (transcendence) to $d=.14$ (purposefulness). Hence, at the sample level, our results confirm previous studies: Calling showed tiny differences across time. A different picture emerges if we analyze absolute changes, irrespective of their sign. In the aggregate, the mean absolute change from $\mathrm{T} 1$ to $\mathrm{T} 2$ and from $\mathrm{T} 2$ to $\mathrm{T} 3$ was $\Delta_{z 1}=.57$ and $\Delta_{z 2}=.53$, respectively. Opposite individual trajectories must compensate for each other, concealing the actual amount of intraindividual change. Disaggregated analyses showed that the most stable facet was passion, for which mean absolute changes of $\Delta_{z 1}=.49$ and $\Delta_{z 2}=.46$ were observed. The least stable facet was pervasiveness, for which we observed mean absolute changes of $\Delta_{z 1}=.60$ and $\Delta_{z 2}=.63$. In repeated-measures designs, these are moderate-to-large effect sizes. Very large changes $\left(\Delta_{z}>.8\right)$ were present in $25 \%$ of participants.

Taken at face value, these results might seem incompatible with the notion that calling is a dispositional trait, which is relatively stable by definition. As a comparison parameter, a recent meta-analysis showed that, between ages 22 and 30, the Big Five traits change less than .28 $S D$ (-.01 SD for Openness; Roberts, Walton, \& Viechtbauer, 2006), which means less than .04 $S D$ per year. Yet, clusters of individuals were identified (Morizot \& Blanc, 2003) in which changes 


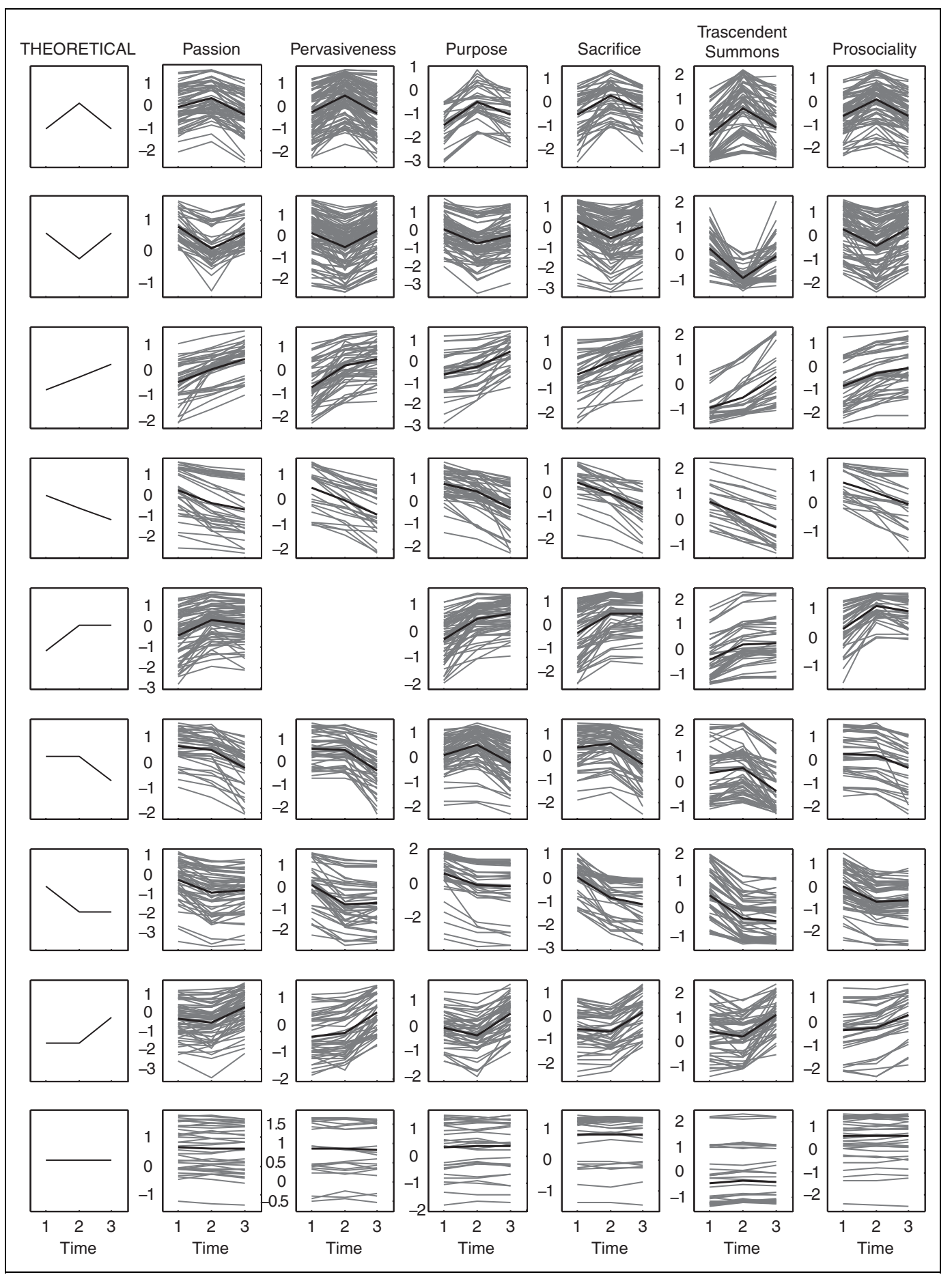

Figure I. Clusters of individuals with similar trajectories of change for each facet of calling. Gray lines represent observed individual trajectories. The thick black line represents the mean trajectory across subjects. Theoretical trajectories are provided in the first column. 
in personality were up to $2 S D$ between ages 17 and 30 . Hence, in order to investigate whether individual trajectories follow similar patterns of change across participants, we conducted a longitudinal cluster analysis.

\section{Changes in Calling at the Individual Level: Clusters of Change}

To investigate how and how much calling changes at the intraindividual level, we preliminarily considered that, for each person and for each time lag, calling can increase, decrease, or stay the same. Hence, we identified nine theoretical trajectories, represented in the left panel of Figure 1. Then, we clustered individuals based on their trajectories of change over time using the $\mathrm{R}$ package "TSclust" (Montero \& Vilar, 2014). This package implements a clustering procedure proposed by Chouakria and Nagabhushan (2007), which is based on the temporal correlation coefficient CORT (Chouakria, 2003). Being a correlation coefficient, the value of CORT ranges between -1 and 1 . A value of 1 means that, over any time interval $\left[t_{i}, t_{i+1}\right]$, the two trajectories increase or decrease simultaneously with the same growth rate. A value of -1 means that the two trajectories show a similar growth rate but opposite directions (one increases whereas the other decreases). Finally, a value of 0 means that there is no monotonicity between the two trajectories and that their growth rates are stochastically linearly independent. By taking into account the dependence between consecutive time points, CORT has been found to outperform classical correlation coefficients when comparing the behavior of two time series (Chouakria \& Nagabhushan, 2007).

The clustering procedure allows the researcher to modulate the contribution of the proximity of trajectories with respect to the behavior (as expressed by coefficient CORT) and their proximity with respect to values (e.g., the distance between scores at any time point). We maximized the contribution of proximity with respect to behavior (i.e., the shape of trajectories). The clustering procedure might have difficulty in producing a cluster of individuals with a stable trajectory (a stability cluster). The coefficient CORT is undefined (CORT $=0 / 0)$ if at least one of the two trajectories is invariant over time (i.e., the same measure is observed in all time points). An undesired result occurs when both the trajectories are invariant over time, that is, the value of CORT is undefined instead of being 1 . In the present work, the clustering procedure divided trajectories with the same monotonicity (i.e., that increased or decreased simultaneously) but different growth rates into different clusters before producing a stability cluster. Therefore, such a stability cluster was not obtained before a large number of clusters was extracted. Given the difficulties of the clustering procedure in producing the stability cluster, we decided to manually assign to this cluster the individuals who showed differences from T1 to T2 and from T2 to T3 that were smaller in size than .1 standard deviations, which are usually denoted as trivial in size (Cohen, 1988). The clustering procedure was implemented to distinguish the remaining individuals. Solutions with nine clusters were estimated and accepted unless similar trajectories were divided into different clusters. In this case, we estimated solutions with one fewer cluster until the more parsimonious solution best approximated the theoretical clusters. This clustering procedure was applied on each facet of calling separately.

The right panels of Figure 1 represent the individual trajectories of change for each cluster and for each facet. The vertical axis of each panel shows the standardized scores of the calling facets under investigation. The black line represents the average trajectory across subjects, and the gray lines represent the trajectory of each individual in that cluster. The number of subjects in each cluster goes from 23 to 102 (mean size $=49, S D=18$ ). The median CORT coefficient between trajectories in the same cluster goes from .91 to .99 , indicating that the solution categorized individuals with very similar trajectories. All of the theoretical clusters have been observed except for the "increasestable" cluster in the pervasiveness facet. As can be seen in Figure 1, individual trajectories can 
Table 2. Median CORT Coefficients Between Trajectories of the Same Individuals by Facets of Calling.

\begin{tabular}{lccccc}
\hline & Passion & Pervasiveness & Purposefulness & Sacrifice & Transcendent summons \\
\hline Pervasiveness & .82 & & & & \\
Purposefulness & .70 & .65 & & & \\
Sacrifice & .89 & .82 & .74 & & \\
Transcendent summons & .41 & .40 & .70 & .41 & \\
Prosocial orientation & .36 & .37 & .72 & .43 & .56 \\
\hline
\end{tabular}

Note. $N=434$.

be extremely variable. The same subject could go three standard deviations down from T1 to T2, and then three standard deviations up from T2 to T3 (see, e.g., the "decrease-increase" cluster for transcendence).

\section{Are Individual Changes in Calling Consistent Across Components?}

Consistently with our multidimensional conceptualization and operationalization of calling, we expect to observe similar developmental trajectories in different components of calling within the same individuals. Hence, we analyzed the degree of consistency between individual changes across facets of calling, computing for each individual the CORT coefficients between the trajectories of the facets of calling. Results show that individuals who show a trajectory in a facet tended to show a similar trajectory in other facets. Yet, the degree of consistency depends on facets. Table 2 shows the median CORT coefficients across individuals, disaggregated by facets of calling. We observed a moderate-to-strong correlation between the trajectories of different facets. Overall, prosocial orientation and transcendent summons changed more independently than the other facets. Passion, sacrifice, and pervasiveness tended to change very consistently with one another.

\section{Predictors and Outcomes of Change in Calling}

So far, we have observed that calling is extremely variable and that developmental trajectories can take any possible shape. In this section, we investigate whether age, gender, mean grade, work experience, and living a calling have an impact on individual change trajectories. To this end, we specified and estimated an unconditional latent growth curve model (LGCM; Bollen \& Curran, 2006; Little, 2013). Being a multilevel SEM, this model estimates the trajectories of change in terms of slopes and intercepts. In LGCM, latent variables for both the initial level (intercept) and the rate of change across time (slope) are specified. Hence, change trajectories were modeled as a distribution across subjects whose mean and standard deviation are estimated. As per standard practice in latent growth curve modeling, the loadings of the intercept factor were all constrained to 1 . This set of constraints gives meaning to the intercept factor, which can be interpreted as the distribution of the initial level of individual trajectories. The shape of the trajectories was defined by constraining at 0 and 1 the loadings from the slope factor to the observed measure of calling at T1 and T2, respectively. The unconstrained estimation of the loading at $\mathrm{T} 3$ gives the trajectory a shape and informs the amount of change that happens from T2 to T3 in terms of the proportion of change that occurred from $\mathrm{T} 1$ to $\mathrm{T} 2$. For instance, an estimated loading of 2 at T3 would indicate a positive linear growth, whereas an estimate of 4 would indicate a positive quadratic growth. Hence, the slope factor can be interpreted as a distribution of the shapes of the growth curves across individuals.

An LGCM was estimated for each facet of calling. The differences in parameter estimates across models were trivial. Hence, for conciseness and the purposes of presentation, we computed a composite score of calling, averaging the scores of the six facets, and used this variable in the 


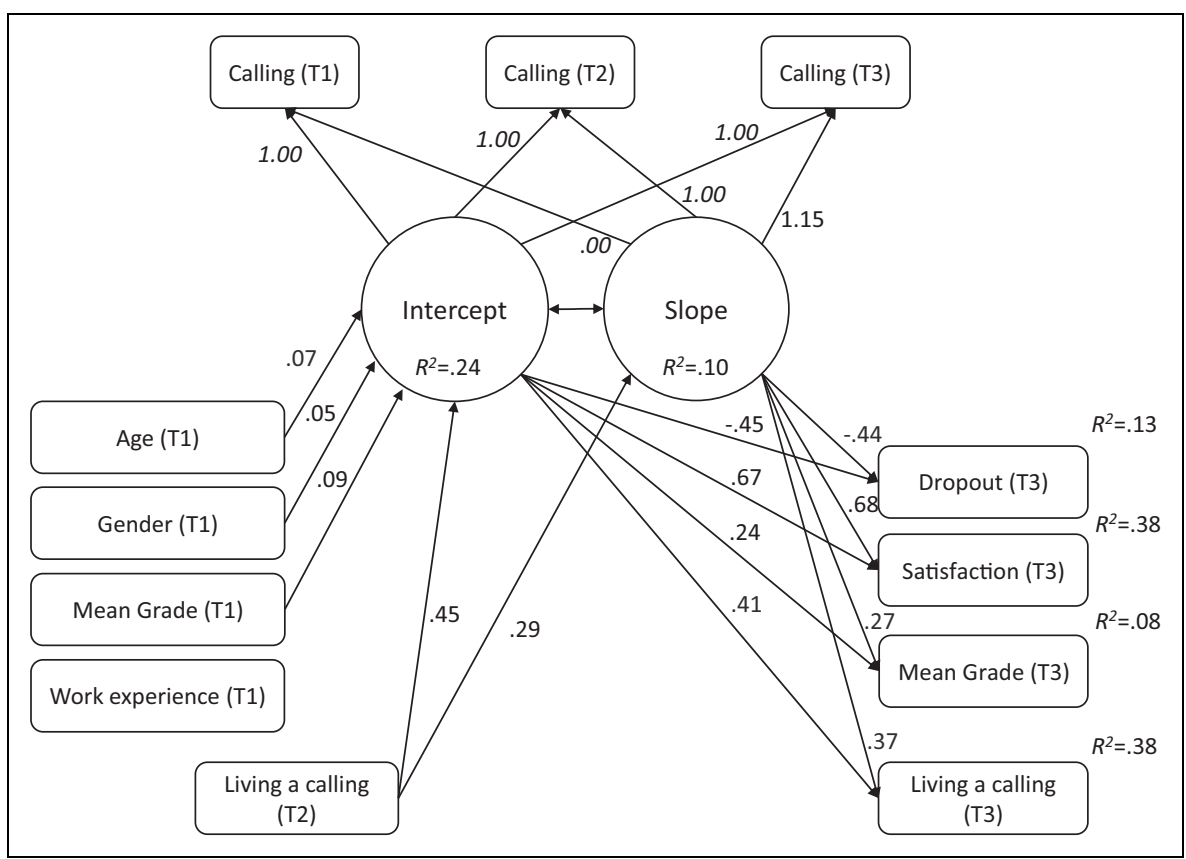

Figure 2. Predictors and outcomes of changes in calling. Only significant paths involving the intercept and slope of the growth curve are reported. All estimates are standardized except for the loading of Calling (T3) to the slope factor, which is more interpretable if not standardized. All possible relationships among predictors, outcomes, intercept, and slope, including paths, errors, residuals, and correlations have been estimated but are omitted for clarity from the figure. Italicized numbers are fixed values that define the meaning of the constructs, identify the model, and set the scale. $\chi^{2}(7 \mathrm{I})=61.52, p<.00 \mathrm{I}, \mathrm{CFI}=.99, \mathrm{RMSEA}=.019,95 \% \mathrm{Cl}[.014, .024]$.

model depicted in Figure $2{ }^{2}$ In this model, the unstandardized T3 loading was 1.15, meaning that the change that occurred at T3 was $85 \%$ less than the amount of change that we would have expected, assuming linear growth. In other words, $78 \%$ of the total change occurred before T2. Although fluctuations are in general very large, they decreased during the second year. Hence, calling tends to stability, and this result is compatible with the hypothesis according to which we observe calling in a phase of life in which it is highly malleable. This developmental pattern has been previously observed for vocational interests (Low et al., 2005), so we reasoned that it would have been worth testing whether changes in calling are predicted by the age of respondents or by their work experience. It may be that older students and students in employment change less than younger, full-time students. Hence, we added participants' age and work experience to the model. We also included gender and mean grade as predictors, and mean grade, dropout intentions, and academic satisfaction as outcomes. For all outcomes and all predictors, we specified relations with both the intercept and the slope of growth trajectories. The final model has five predictors (age, gender, work experience, mean grade at T1, and living out a calling at T2) and four outcomes of change (living out a calling, mean grade, academic satisfaction, and dropout intentions at T3). Results are reported in Figure 2, which only displays significant paths. The left side of Figure 2 displays the relations between the predictors and the growth trajectories (intercept and slope). We can see that all predictors influence the initial level of having a calling (intercept factor). Yet the size of the relations, which is provided by the estimate of the regression path between predictors and the latent factors, is trivial for age, gender, and mean grade. Female, experienced, and older students tend to exhibit a slightly higher initial level of calling. The relations between age, gender, mean grade, and work experience are not 
significant for the slope factor; hence, the rate of change in calling is not influenced by these variables. The strongest predictor of the intercept and the slope of the growth trajectory is living out a calling. The more the students felt that they were living out their calling, the higher they started and the more their calling increased across 2 years.

The right side of Figure 2 displays outcomes of changes in the perception of having a calling. We can see that both the initial level (intercept) and the rate of change (slope) positively predicted the extent to which students reported that they were living out a calling at T3. Finally, we observed that both the intercept and the slope of the growth trajectory significantly predict participants' dropout intentions, academic satisfaction, and mean grade. The higher participants' calling was at T1 (intercept), and the faster their calling grew over the years (slope), the more participants were satisfied with their program, received higher grades, were less willing to leave the program, and lived out their calling at T3. The strongest effects were observed for academic satisfaction and living a calling. The intercept and slope factors account for $38 \%$ of the variance in academic satisfaction and living a calling at T3. The variance accounted for by the intercept and slope factors is much smaller for dropout intentions $\left(R^{2}=.13\right)$ and mean grade $\left(R^{2}=.08\right)$.

These results clearly suggest that the development of a calling is fostered by the extent to which individuals live it out. Individuals who are living out a calling are more likely to have higher and steeper growth trajectories. In parallel, the more a calling grows, the more individuals feel that they are living it out. Having and living a calling are reciprocally related. In addition, we observed that both the intercept and the slope of the change trajectories strongly and positively influenced important academic outcomes such as dropout intentions, mean grade, and academic satisfaction at T3.

\section{Discussion}

Results of previous studies on the development of calling are inconclusive. Different authors observed different temporal changes: At the sample level, calling increased (Duffy, Douglass, et al., 2014), decreased (Duffy, Manuel, Borges, \& Bott, 2011), and remained substantially stable (Bott \& Duffy, 2015; Dobrow, 2013; Hirschi \& Herrmann, 2013; Praskova, Hood, \& Creed, 2014). Our findings account for these discrepancies: Interindividual differences in change trajectories can explain the inconsistency of results obtained at the sample level of analysis. We observed that intraindividual changes in calling can be huge and that individual trajectories are very different from one another. These individual variations would not be surprising if we assumed that a calling changes as a function of the interaction between an individual and environmental conditions, events, and situations. Pending new evidence that contradicts or limits the generalizability of these results, we suggest that the calling construct at least moderately depends on the interaction with the environment rather than on stable individual factors such as genes, values, or personality traits. The notion that a calling is largely influenced by state-like components is also supported by the moderate intensity of autocorrelations ( $r=.5$ to .7 ) that have been reported by Bott and Duffy (2015), Hirschi and Herrmann (2013), Dobrow and Heller (2015), Dobrow (2013), Duffy, Manuel, Borges, and Bott (2011), and Duffy, Douglass, et al. (2014). However, we should only tentatively accept the conclusion that calling is a state (as opposed to a trait) concept. Indeed, we did not include in our design a comparison parameter such as extroversion or conscientiousness against which the developmental patterns of calling could have been more meaningfully interpreted.

The implications of our results for the conceptualization of calling depend on the generalizability of the observations. If these results are validated and generalized to the whole life span, then we will be able to conclude that calling is not a stable disposition, but a state that heavily depends on interactions with the environment, such as experiences or feedback in the calling's domain. However, we might have observed calling during a phase of life in which it is more flexible, perhaps because participants were in the process of building it. Indeed, results of the LGCM showed that the 
growth curve of calling tends to stability, as changes between T1 and T2 are more intense than those from T2 to T3. Although the effects of age or employment status on calling changes are tiny and practically trivial, a pattern of stability is more likely to be present in older students. The mean age of subjects in the stability cluster $\left(M_{\text {age }}=22.96, S D=5.47, N=147\right)$ was slightly higher than that of the other clusters $\left(M_{\text {age }}=21.62, S D=4.46, N=287\right)$. These results are compatible with the notion that we observed calling in a phase of life in which it is highly malleable. Calling could behave like vocational interests: It may change, even dramatically, during college and then stabilize in adulthood or during the first experiences of work socialization (Low et al., 2005). In light of these considerations, we can hypothesize that calling is a dispositional trait whose development occurs during the first experiences in the calling domain, such as college or any other vocational development program. We look forward to longitudinal research on working adults for whom stability of calling is expected. In the absence of such research, any conclusion regarding the stability of calling, or its state or trait nature, would be premature.

In this study, we used a model of calling (Vianello et al., 2018) that merges together many different facets (UMCS). We observed that these facets tend to covary, that is, share the same trajectory of change. This result can be interpreted as further evidence that the six dimensions are facets of the same construct. Yet the large range of correlations between .36 and .89 suggests that the dimensions of a calling can develop independently from one another and that some facets are more independent than others. Specifically, we observed that prosocial orientation and transcendent summons tend to change more independently than the other components of calling. This result may raise questions concerning the factor structure of the UMCS because it could be interpreted as supporting the notion that prosocial orientation and transcendent summons are not part of the same construct. This interpretation is debatable. On the one hand, we think that it is normal for the components of a multidimensional construct to develop independently from one another because they are likely to be influenced by different experiences. For instance, personality traits develop differently throughout life (Srivastava, John, Gosling, \& Potter, 2003), yet they were consistently shown to form two higher order factors (Digman, 1997, Schermer \& Goffin, 2018). On the other hand, Vianello et al. (2018) reported that prosocial orientation and transcendent summons showed small second order loadings in college students and adequate loadings in a sample of workers. Altogether, these results may support the hypothesis that prosocial orientation and transcendent summons become part of a calling during a later stage of its development.

One more important result of this study concerns the role of academic performance. We found that mean grade is an outcome of calling rather than an information used by individuals to understand whether they have a calling. The tiny or null relation that we observed between mean grade at $\mathrm{T} 1$ and the rate of change in calling suggests that specific skills in the calling's domain are not a necessary condition for the development of a calling. This finding is partially consistent with Dobrow (2013), who found that an individual's ability in the calling's domain was neither a predictor of initial levels of the calling nor of temporal changes in the calling; this adds to the literature the demonstration that ability is a consequence, rather than a predictor, of levels and changes in calling. In our model, mean grade at T3 is influenced by both the intercept and the slope of the growth curve: Higher levels and increases in calling improve academic performance. We might speculate that this relation is mediated by commitment and dedication to the calling's domain. We hope that future research will test this hypothesis and, more generally, investigate the process by which calling fosters success. We also observed that both the intercept and the slope of the growth curve predict dropout intentions and academic satisfaction. Not only do students with higher levels of calling show higher academic satisfaction and lower dropout intentions at T3, but also so do those that, regardless of their initial level, increased their calling. This result is of great practical importance since it represents the first empirical evidence that the process of developing a calling in itself is beneficial to the individual and predicts academic achievement. 
Finally, and perhaps most importantly, we showed that living out a calling is the favored path toward the growth of a calling. We found support for Hall and Chandler's (2005) cyclical model, and we identified a virtuous cycle between having and living out a calling, such that they reciprocally foster each other. These results support some of the predictions made by the WCT (Duffy et al., 2018), according to which a reciprocal relation exists between perceiving and living a calling. We found that higher levels of a calling and changes in a calling are both outcomes and predictors of higher levels of living out a calling. On the other hand, higher levels of living out a calling are both predictors and outcomes of levels of and changes in calling. We suggest that environmental opportunities to live out a calling are key, not only for experiencing meaningfulness at work, career commitment, and the general well-being associated with living out a calling but also for the development of a calling itself. In agreement with the WCT (Duffy et al., 2018), we believe that a calling develops through experiences in the calling's domain, and the perception of living out a calling through these experiences is used by individuals to strengthen their beliefs of actually having a calling. On the other hand, the lack of opportunities to live out a calling will inevitably weaken individuals' beliefs in actually having a calling. This result is also in agreement with the role attributed to the person-environment fit by Hagmaier and Abele (2012), and it is consistent with Praskova, Creed, and Hood's (2015) definition of calling as "a developmental and dynamic construct" (p. 102).

\section{Limitations of the Present Study}

Our results clearly represent a starting point rather than an end point: We accounted for $10 \%$ of all changes in calling and look forward to research that can help us understand which other factors account for the remaining $90 \%$. Second, our sample was composed of college students, so we could not test our hypothesis regarding the stabilization of calling during later adulthood. We hope future research will investigate how and how much calling changes in working adults and that it will thoroughly examine the virtuous cycle between having a calling and the feeling of living it out during professional activities. Furthermore, the generalizability of our results is still to be proven. Although it is likely that replications of our study on college students would observe the same pattern of results, we urge readers not to generalize these results to workers or ages other than young adulthood. Third, our measure of living out a calling was composed of only 1 item and was specifically referred to students' academic experience. This is likely to exclude students who live a calling outside of their studies. As a consequence, we might have underestimated the number of students living out a calling. Also, living a calling during college might be a complex experience. Students may be aware that they are actually learning something that they feel called to, but they might lack the engagement in activities that help them to live out their calling. Hence, our measure of living a calling might not differentiate well how much participants were living a calling from their perception of having one, thus inflating the relation between them. ${ }^{3}$ Although we believe that attending classes, reading course materials, discussing topics, work placements, and internships are activities that inform students about how much they are living their calling toward a domain, we cannot rule out the possibility that our estimates were bigger than they would have been if participants had been working in, rather than learning, the calling domain. Future studies might investigate this point and consider the development of a scale for measuring the construct of living a calling in college students. Finally, a limit of this research is imposed by the time lag that we employed. Our choice was informed by the implicit assumption that calling is a dispositional trait and by previous studies showing basically no short-term changes in calling. In light of the results discussed in this article, we would now choose a shorter time lag. Although we suggest interpreting the huge intraindividual variability as a sign of its development, it is necessary to exclude that changes in calling are exceedingly rapid and frequent. If high intraindividual variability is observed daily or weekly, then conceiving calling as a state-like construct would probably be wiser. 


\section{Conclusion and Future Prospects}

This study answers some questions and opens many others. In general, our results emphasize how little we know about the development of a calling. The approach that previous research followed in conducting the analysis focused on sample-level averages. We wonder whether this approach might prevent us from analyzing the dynamic nature of calling. Hopefully, future research will consider adopting a person-specific approach to the study of calling development. Indeed, we observed that, across individuals, calling develops in very different ways. Also, we observed that these change trajectories are at least partially influenced by the extent to which people can live out their calling. Finally, we showed that positive outcomes are not only related to high levels of calling but also to changes. When controlling for the initial level of the growth trajectory, an increase in calling determines a longitudinal increase in important academic outcomes such as dropout, mean grade, and satisfaction with the program.

We still can't provide a definitive answer on the state-or-trait nature of a calling nor on its origin, but we paved the way to future studies by showing that this answer may be found by investigating person-environment interactions.

\section{Authors' Note}

Michelangelo Vianello coordinated the project, designed the study, developed materials, collected and analyzed the data, and wrote the report. Elisa Maria Galliani developed materials, analyzed the data, and wrote the report. Anna Dalla Rosa developed materials, collected and analyzed the data, and wrote the report. Pasquale Anselmi analyzed the data and wrote the report. Elisa Maria Galliani is now affiliated with Department of Political and Juridical Sciences and International Studies.

\section{Declaration of Conflicting Interests}

The author(s) declared no potential conflicts of interest with respect to the research, authorship, and/or publication of this article.

\section{Funding}

The author(s) disclosed receipt of the following financial support for the research, authorship, and/or publication of this article: This work was supported by an MIUR grant [grant number PRIN2012 LATR9N] and by a Departmental grant [SID16_01] awarded to the first author. The funding source had no involvement in study design, in the collection, analysis, and interpretation of data; in the writing of the report; or in the decision to submit the article for publication.

\section{Notes}

1. We would like to clarify that our parallelism with Maslow's theory of needs ends here. We are not suggesting that career calling can be interpreted in light of other needs nor that the relations between calling and Maslow's lower order needs are the same that Maslow theorized for self-actualization. We are also not suggesting that people may be motivated to pursue a calling only after they have satisfied their lower order needs (e.g., belonging, love, and respect). Indeed, there is no support for Maslow's simple frustration hypothesis, which was falsified by Alderfer (1969).

2. Model estimates for each facet can be obtained from the authors upon request.

3. We thank an anonymous reviewer for suggesting this possibility.

\section{References}

Aitken, N. D. (1982). College student performance, satisfaction and retention: Specification and estimation of a structural model. The Journal of Higher Education, 53, 32-50. doi:10.1080/00221546.1982.11780423

Alderfer, C. P. (1969). An empirical test of a new theory of human needs. Organizational Behavior and Human Performance, 4, 142-175. doi:10.1016/0030-5073(69)90004-X 
Bollen, K. A., \& Curran, P. J. (2006). Latent curve models: A structural equation perspective. Hoboken, NJ: Wiley.

Bott, E. M., \& Duffy, R. D. (2015). A two-wave longitudinal study on career calling among undergraduates: Testing for predictors. Journal of Career Assessment, 23, 250-264. doi:10.1177/1069072714535030

Bunderson, J. S., \& Thompson, J. A. (2009). The call for the wild: Zookeepers, callings, and the double-edge sword of deeply meaningful work. Administrative Science Quarterly, 54, 32-57. doi:10.2189/asqu.2009.54.1.32

Chouakria, A. D. (2003). Compression technique preserving correlations of a multivariate temporal sequence. In M. R. Berthold, H. J. Lenz, E. Bradley, R. Kruse, \& C. Borgelt (Eds.), Advances in intelligent data analysis (pp. 566-577). Berlin, Heidelberg: Springer.

Chouakria, A. D., \& Nagabhushan, P. N. (2007). Adaptive dissimilarity index for measuring time series proximity. Advances in Data Analysis and Classification, 1, 5-21. doi:10.1007/s11634-006-0004-6

Cohen, J. (1988). Statistical power analysis for the behavioural sciences. New York, NY: Lawrence Erlbaum.

Dalla Rosa, A., Galliani, E. M., \& Vianello, M. (2014). Theories and measures of occupational calling: A review and research agenda. Educational Reflective Practices, 2, 99-121. doi:10.3280/ERP2014-002007

Dalla Rosa, A., Galliani, E. M., \& Vianello, M. (2017). An integrative model of career calling and metaanalysis of its nomological network. In V. Boffo, M. Fedeli, F. Lo Presti, C. Melacarne, \& M. Vianello (Eds.), Employability, teaching and learning, and guidance: New strategies in higher education. London, England: Pearson.

Dalla Rosa, A., Vianello, M., \& Anselmi, P. (2017). Longitudinal predictors of the development of a calling: New evidence for the a posteriori hypothesis. Manuscript submitted for publication.

Digman, J. M. (1997). Higher-order factors of the Big Five. Journal of Personality and Social Psychology, 73, 1246.

Dik, B. J., \& Duffy, R. D. (2009). Calling and vocation at work. The Counselling Psychologist, 37, 424-450. doi: $10.1177 / 0011000008316430$

Dik, B. J., Eldridge, B. M., Steger, M. F., \& Duffy, R. D. (2012). Development and validation of the Calling and Vocation Questionnaire (CVQ) and Brief Calling Scale (BCS). Journal of Career Assessment, 20, 242-263. doi: $10.1177 / 1069072711434410$

Dobrow, S. (2013). Dynamics of calling: A longitudinal study of musicians. Journal of Organizational Behavior, 34, 431-452. doi:10.1002/job.1808

Dobrow, S., \& Heller, D. (2015). Follow your heart or your head? A longitudinal study of the facilitating role of calling and ability in the pursuit of a challenging career. Journal of Applied Psychology, 100, 695-712. doi: 10.1037/a0038011

Dobrow, S., \& Tosti-Kharas, J. (2011). Calling: The development of a scale measure. Personnel Psychology, 64, 1001-1049. doi:10.1111/j.1744-6570.2011.01234.x

Drolet, A. L., \& Morrison, D. G. (2001). Do we really need multiple-item measures in service research? Journal of Service Research, 3, 196-204. doi:10.1177\%2F109467050133001

Duffy, R. D., Allan, B. A., Autin, K. L., \& Bott, E. M. (2013). Calling and life satisfaction: It's not about having it, it's about living it. Journal of Counseling Psychology, 60, 42-52. doi:10.1037/a0030635

Duffy, R. D., Allan, B. A., Autin, K. L., \& Douglass, R. P. (2014). Living a calling and work well-being: A longitudinal study. Journal of Counseling Psychology, 61, 605-615. doi:10.1037/cou0000042

Duffy, R. D., Allan, B. A., \& Bott, E. M. (2012). Calling and life satisfaction among undergraduate students: Investigating mediators and moderators. Journal of Happiness Studies, 13, 469-479. doi:10.1007/s10902011-9274-6

Duffy, R. D., \& Autin, K. L. (2013). Disentangling the link between perceiving a calling and living a calling. Journal of Counseling Psychology, 60, 219-227. doi:10.1037/a0031934

Duffy, R. D., Autin, K. L., Allan, B. A., \& Douglass, R. P. (2015). Assessing work as a calling: An evaluation of instruments and practice recommendations. Journal of Career Assessment, 23, 351-366. doi:10.1177/ 1069072714547163 
Duffy, R. D., Bott, E. M., Allan, B. A., Torrey, C. L., \& Dik, B. J. (2012). Perceiving a calling, living a calling, and job satisfaction: Testing a moderated, multiple mediator model. Journal of Counseling Psychology, 59, 50-59. doi:10.1037/a0026129

Duffy, R. D., Dik, B. J., Douglass, R. P., England, J. W., \& Velez, B. L. (2018). Work as a calling: A theoretical model. Journal of counseling psychology, 65, 423. doi:10.1037/cou0000276

Duffy, R. D., \& Dik, B. J. (2013). Research on calling: What have we learned and where are we going? Journal of Vocational Behavior, 83, 428-436. doi:10.1016/j.jvb.2013.06.006

Duffy, R. D., Douglass, R. P., Autin, K. L., \& Allan, B. A. (2014). Examining predictors and outcomes of career calling among undergraduates students. Journal of Vocational Behavior, 85, 309-318. doi:10.1016/j.jvb. 2014.08.009

Duffy, R. D., Manuel, R. S., Borges, N. J., \& Bott, E. M. (2011). Calling, vocational development, and well being: A longitudinal study of medical students. Journal of Vocational Behavior, 79, 361-366. doi:10.1016/ j.jvb.2011.03.023

Duffy, R. D., \& Sedlacek, W. E. (2007). The presence of and search for a calling: Connections to career development. Journal of Vocational Behavior, 70, 590-601. doi:10.1016/j.jvb.2007.03.007

Eicher, V., Staerklé, C., \& Clémence, A. (2014). I want to quit education: A longitudinal study of stress and optimism as predictors of school dropout intention. Journal of adolescence, 37, 1021-1030. doi:10.1016/j. adolescence.2014.07.007

Gazica, M. W., \& Spector, P. E. (2015). A comparison of individuals with unanswered calling to those with no calling at all. Journal of Vocational Behavior, 91, 1-10. doi:10.1016/j.jvb.2015.08.008

Goodman, J. S., \& Blum, T. C. (1996). Assessing the Non-Random Sampling Effects of Subject Attrition in Longitudinal Research. Journal of Management, 22(4), 627-652. doi:10.1177/014920639602200405

Hagmaier, T., \& Abele, A. E. (2012). The multidimensionality of calling: conceptualization, measurement, and a bicultural perspective. Journal of Vocational Behavior, 81, 39-51. doi:10.1016/j.jvb.2012.04.001

Hall, D. T., \& Chandler, D. E. (2005). Psychological success: When the career is a calling. Journal of Organizational Behavior, 26, 155-176. doi:10.1002/job.301

Heise, D. R. (1969). Separating Reliability and Stability in Test-Retest Correlation. American Sociological Review, 34(1), 93-101. doi:10.2307/2092790

Hirschi, A., \& Herrmann, A. (2013). Calling and career preparation: Investigating developmental patterns and temporal precedence. Journal of Vocational Behavior, 83, 51-60. doi:10.1016/j.jvb.2013.02.008

Hunter, I., Dik, B. J., \& Banning, J. H. (2010). College students' perceptions of calling in work and life: A qualitative analysis. Journal of Vocational Behavior, 76, 178-186. doi:10.1016/j.jvb.2009.10.008

Koltko-Rivera, M. E. (2006). Rediscovering the later version of Maslow's hierarchy of needs: Selftranscendence and opportunities for theory, research, and unification. Review of General Psychology, 10, 302-317. doi:10.1037/1089-2680.10.4.302

Little, T. D. (2013). Longitudinal structural equation modeling. New York, NY: Guilford Press.

Low, K. S. D., Yoon, M., Roberts, B. W., \& Rounds, J. (2005). The stability of vocational interests from early adolescence to middle adulthood: A quantitative review of longitudinal studies. Psychological Bulletin, 131, 713-737. doi:10.1037/0033-2909.131.5.713

Maslow, A. H. (1954). Personality and motivation. Harlow, England: Longman.

Maslow, A. H. (1971). The farther reaches of human nature. Oxford, England: Viking.

Meredith, W. (1993). Measurement invariance, factor analysis and factorial invariance. Psychometrika, 4, 525-543. doi:10.1007/BF02294825

Miller, J., \& Schwartz, W. (2017). Implications of individual differences in on-average null effects. Journal of Experimental Psychology: General. Advance online publication. doi:10.1037/xge0000367

Montero, P., \& Vilar, J. A. (2014). TSclust: An R package for time series clustering. Journal of Statistical Software, 62. doi:10.18637/jss.v062.i01 
Morizot, J., \& Blanc, M. L. (2003). Searching for a developmental typology of personality and its relations to antisocial behaviour: A longitudinal study of an adjudicated men sample. Criminal Behaviour and Mental Health, 13, 241-277. doi:10.1111/j.1467-6494.2004.00307.x

Nagy, M. S. (2002). Using a single-item approach to measure facet job satisfaction. Journal of Occupational and Organizational Psychology, 75, 77-86. doi:10.1348/096317902167658

Nauta, M. M. (2007). Assessing college students' satisfaction with their academic majors. Journal of Career Assessment, 15, 446-462. doi:10.1177\%2F1069072707305762

Nunnally, J. C., \& Bernstein, I. H. (1994). Psychometric theory (McGraw-Hill Series in Psychology) (Vol. 3). New York, NY: McGraw-Hill.

Perez, T., Cromley, J. G., \& Kaplan, A. (2014). The role of identity development, values, and costs in college STEM retention. Journal of Educational Psychology, 106, 315. doi: 10.1037/a0034027

Praskova, A., Creed, P. A., \& Hood, M. (2015). The development and initial validation of a career calling scale for emerging adults. Journal of Career Assessment, 23, 91-106. doi:10.1177/1069072714523089

Praskova, A., Hood, M., \& Creed, P. A. (2014). Testing a calling model of psychological career success in Australian young adults: A longitudinal study. Journal of Vocational Behavior, 85, 125-135. doi:10.1016/j. jvb.2014.04.004

Roberts, B. W., Walton, K. E., \& Viechtbauer, W. (2006). Patterns of mean-level change in personality traits across the life course: A meta-analysis of longitudinal studies. Psychological Bulletin, 132(1), 1-25.

Scarpello, V., \& Campbell, J. P. (1983). Job satisfaction: Are all the parts there? Personnel psychology, 36, $577-600$.

Schermer, J. A., \& Goffin, R. D. (2018). A tale of two general factors of personality in relation to intelligence and validity measures. Personality and Individual Differences, 124, 111-116. doi:10.1016/j.paid.2017.12. 010

Srivastava, S., John, O. P., Gosling, S. D., \& Potter, J. (2003). Development of personality in early and middle adulthood: Set like plaster or persistent change? Journal of Personality and Social Psychology, 84, 1041. doi:10.1037/0022-3514.84.5.1041

Strahan, S., \& Credé, M. (2015). Satisfaction with college: Re-examining its structure and its relationships with the intent to remain in college and academic performance. Journal of College Student Retention: Research, Theory \& Practice, 16, 537-561. doi:10.2190/CS.16.4.d

Thompson, J. A., \& Bunderson, J. S. (2019). Research on Work as a Calling ... and How to Make It Matter. Annual Review of Organizational Psychology and Organizational Behavior, 6, 421-443.

Tóth-Király, I., Bőthe, B., Jánvári, M., Rigó, A., \& Orosz, G. (2018). Longitudinal trajectories of passion and their individual and social determinants: A latent growth modeling approach. Journal of Happiness Studies. Advance online publication. doi:10.1007/S10902-018-0059-Z

University of Cincinnati, College of Medicine. (2010, June 10). Final report on the 2008 class profile of matriculants. Retrieved from http://comdo-wcnlb.uc.edu/PDFdocuments/Admissions/AdmissionsMatriculantProfile. pdf

Vianello, M., Dalla Rosa, A., Anselmi, P., \& Galliani, E. M. (2018). Validity and measurement invariance of the Unified Multidimensional Calling Scale (UMCS): A three-wave survey study. PLOS ONE, 13, e0209348. doi:10.1371/journal.pone.0209348

Wrzesniewski, A., McCauley, C., Rozin, P., \& Schwartz, B. (1997). Jobs, careers, and callings: People's relations to their work. Journal of Research in Personality, 31, 21-33. doi:10.1006/jrpe.1997.2162

Zhang, C., Dik, B. J., Wei, J., \& Zhang, J. (2015). Work as a calling in China: A qualitative study of Chinese college students. Journal of Career Assessment, 23, 236-249. doi:10.1177/1069072714535029

Zhang, C., Herrmann, A., Hirschi, A., Wei, J. \& Zhang, J. (2015). Assessing calling in Chinese college students: Development of a measure and its relation to hope. Journal of Career Assessment, 23, 582-596. doi:10. $1177 / 1069072715595804$ 